\title{
Porous Silicon Formation by Metal-Assisted Chemical Etching
}

\author{
M. Lipinski ${ }^{a, *}$, J. Cichoszewski ${ }^{b}$, R.P. Socha ${ }^{c}$ And T. Piotrowski ${ }^{d}$ \\ ${ }^{a}$ Institute of Metallurgy and Materials Science, PAS, W.S. Reymonta 25, 30-059 Cracow, Poland \\ ${ }^{b}$ Institute of Physical Electronics, University of Stuttgart, Pfaffenwaldring 47, 70569 Stuttgart, Germany \\ ${ }^{c}$ Institute of Catalysis and Surface Chemistry PAS, Niezapominajek 8, 30-239 Cracow, Poland \\ ${ }^{d}$ Institute of Electron Technology, al. Lotników 32/46, 02-668 Warsaw, Poland
}

\begin{abstract}
The method of metal-assisted chemical etching produces a porous silicon layer. Palladium particles are deposited on both: multi-crystalline and Czochralski grown mono-crystalline Si wafers by immersing them in $\mathrm{PdCl}_{2}$ solution for 1 to $3 \mathrm{~min}$. X-ray photoelectron spectroscopy analysis of $\mathrm{Pd}$ clusters shows a decrease in $\mathrm{Pd}$ metal fraction by prolonged immersion time $t$ from $F_{\mathrm{Pd}}=71.2 \%$ for $t=1$ min to $F_{\mathrm{Pd}}=61.4 \%$ for $t=3 \mathrm{~min}$ due to $\mathrm{Pd}$ oxidation process. Porous silicon forms by metal-assisted chemical etching in a $\mathrm{HF}: \mathrm{H}_{2} \mathrm{O}_{2}$ solution for 1 to $3 \mathrm{~min}$. Photoluminescence of metal-assisted chemical etched samples exhibits the peak with a maximum of $\mathrm{t}$ at $\lambda=650 \mathrm{~nm}$ independent of the etching time. Simultaneously, the intensity of the photoluminescence spectra strongly decreases for extended etching time $t=3 \mathrm{~min}$. This behavior is attributed to increasing layer macroporosity, which strongly reduces amount of light emitting nanocrystallites.
\end{abstract}

PACS numbers: 81.16.Rf, 81.05.Rm, 78.55.Mb, 61.43.Gt, 78.67.Bf

\section{Introduction}

Since Canham [1] discovered in 1990 visible light emission of porous silicon (PS) under UV illumination, PS attracts a lot of attention as a material for optoelectronic application. The light emission is commonly explained by the quantum confinement model. In this model, the absorption in dimensionally confined silicon wires is responsible for visible photoluminescence. PS is usually formed by electrochemical etching with illumination ( $n$-type $\mathrm{Si}$ ) or without ( $p$-type $\mathrm{Si}$ ). It can be also produced by chemical etching in $\mathrm{HNO}_{3}: \mathrm{HF}: \mathrm{H}_{2} \mathrm{O}$ solution (stain etching). Unfortunately, these two methods are not convenient for mass production, as the first one requires an external bias and the second is slow and unreliable.

Since metal-assisted etching (MAE) requires no external bias and enables fast formation of homogeneous PS layers, it is very promising method of porous silicon formation. The MAE bases on deposition of metal particles $(\mathrm{Au}, \mathrm{Ag}, \mathrm{Pt}, \mathrm{Pd})$ as a catalyst for chemical etching in a solution containing $\mathrm{HF}$ and oxidizing species. The thin film of catalytic metal is usually deposited by evaporation or sputtering in vacuum [2-4] or by electroless plating $[5,6]$.

In this paper we deposit $\mathrm{Pd}$ metal particles as a catalyst by immersing $\mathrm{Si}$ wafer in $\mathrm{PdCl}_{2}$ solution for a short period of time (1 to $3 \mathrm{~min}$ ). The optimization of $\mathrm{Pd}$ deposition is carried out by $\mathrm{X}$-ray photoelectron spectroscopy (XPS) and scanning electron microscope (SEM). In the

\footnotetext{
* corresponding author; e-mail: marlipin@wp.pl
}

next step, a metal assisted $\mathrm{HF}: \mathrm{H}_{2} \mathrm{O}_{2}: \mathrm{H}_{2} \mathrm{O}$ etching forms a porous Si. The photoluminescence (PL) measurement investigates the etching time dependence of the microstructure of porous silicon obtained for durations of MAE in $1<t<3$ min range.

\section{Experimental and results}

The starting material are as-cut multi-crystalline silicon (mc-Si) and mono-crystalline Czochralski-grown CZ-Si (111) wafers with a resistivity $0.5<\rho<2 \Omega \mathrm{cm}$. The samples are immersed in an aqueous solution with $\mathrm{PdCl}_{2}$ and $\mathrm{HCl}$ for electroless deposition of palladium particles on the mc-Si surface.

Figures 1a-c show SEM images of a CZ-Si (111) surface with palladium clusters deposited during immersion in $\mathrm{PdCl}_{2}$ solution for 1 to $3 \mathrm{~min}$. The dimension of $\mathrm{Pd}$ particles varies in the range of $10<d<80 \mathrm{~nm}$. The Pd clusters randomly distribute over the silicon surface and form a density $\left(N_{\mathrm{Pd}}\right)$ of surface clusters $N_{\mathrm{Pd}} \approx 4 \times 10^{8} \mathrm{~cm}^{-2}$ after one minute immersion in $\mathrm{PdCl}_{2}: \mathrm{HCl}$ solution.

The X-ray photoelectron spectroscopy technique characterizes the wafer after immersion in $\mathrm{PdCl}_{2}$ solution. The $\mathrm{Mg} K_{\alpha}$ X-ray $(1253.6 \mathrm{eV}, 10 \mathrm{kV}, 20 \mathrm{~mA})$ generates core excitations and a hemispherical analyzer (R4000, Gammadata Scienta) acquires the resulting spectra.

Figure 2 displays the $\mathrm{Pd} 3 d_{5 / 2}$ core excitation spectra for silicon wafer treated in $\mathrm{PdCl}_{2}$ aqueous solution for different immersion times. The $\mathrm{Pd} 3 d_{5 / 2}$ spectrum deconvolutes into 2 components: metallic palladium with binding energy $E_{\mathrm{Pd}}=335.3 \mathrm{eV}$ and $\mathrm{PdO}$ with binding energy $E_{\mathrm{PdO}}=336.4 \div 336.8 \mathrm{eV}[7]$. 
TABLE

The electron binding energies $E$ and ratios $F$ of the $\mathrm{Pd} 3 d_{5 / 2}$ XPS core excitation components for silicon wafer treated in $\mathrm{PdCl}_{2}$ aqueous solution.

\begin{tabular}{c|c|c|c|c|c}
\hline \hline $\begin{array}{c}\text { Pd deposition time } \\
t[\mathrm{~min}]\end{array}$ & \multicolumn{2}{|c|}{ Metallic $\mathrm{Pd}$} & \multicolumn{2}{c|}{$\mathrm{PdO}$} & \multicolumn{1}{c}{$\begin{array}{c}\mathrm{Pd} / \mathrm{Si} \text { atomic surface } \\
\text { ratio } F_{\mathrm{Pd} / \mathrm{Si}} \times 10^{-3}\end{array}$} \\
\cline { 2 - 6 } & $E_{\mathrm{Pd}}[\mathrm{eV}]$ & $F_{\mathrm{Pd}}[\%]$ & $E_{\mathrm{PdO}}[\mathrm{eV}]$ & $F_{\mathrm{PdO}}[\%]$ & 4.8 \\
2 & 335.3 & 71.2 & 336.8 & 28.8 & 6.8 \\
3 & 335.3 & 69.5 & 336.6 & 30.5 & 8.9
\end{tabular}
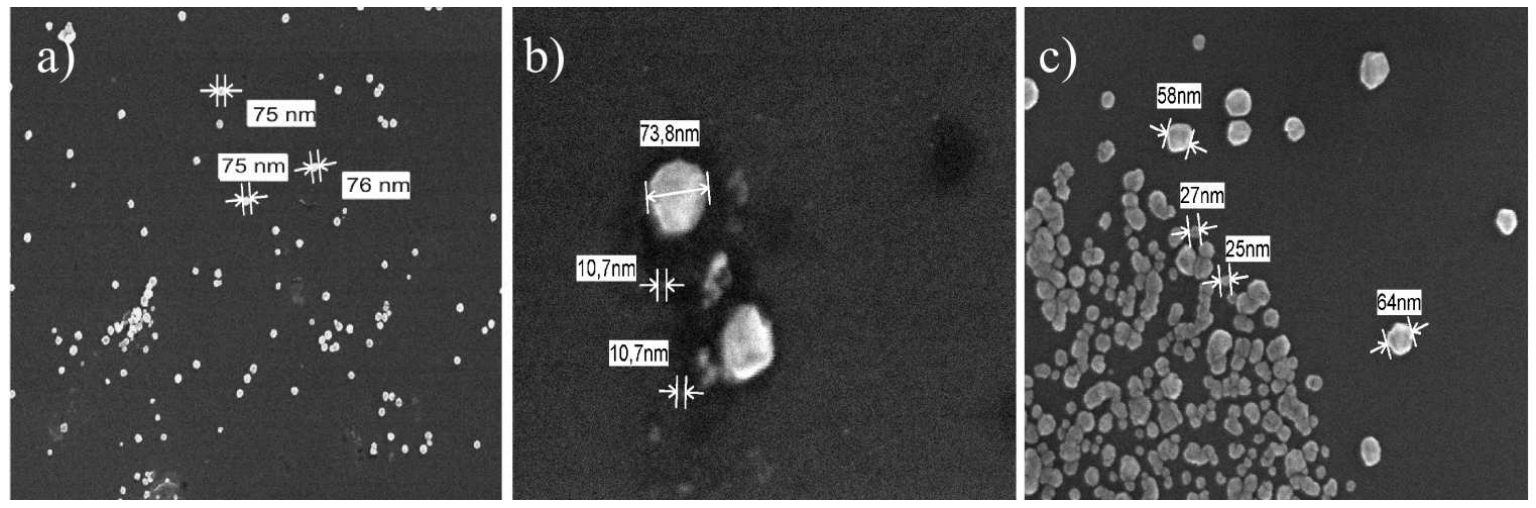

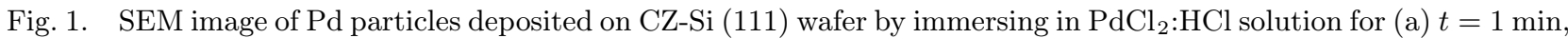
(b) $t=2 \mathrm{~min}$, (c) $t=3 \mathrm{~min}$. The $\mathrm{Pd}$ particle dimension varies in the range of $10<d<80 \mathrm{~nm}$.
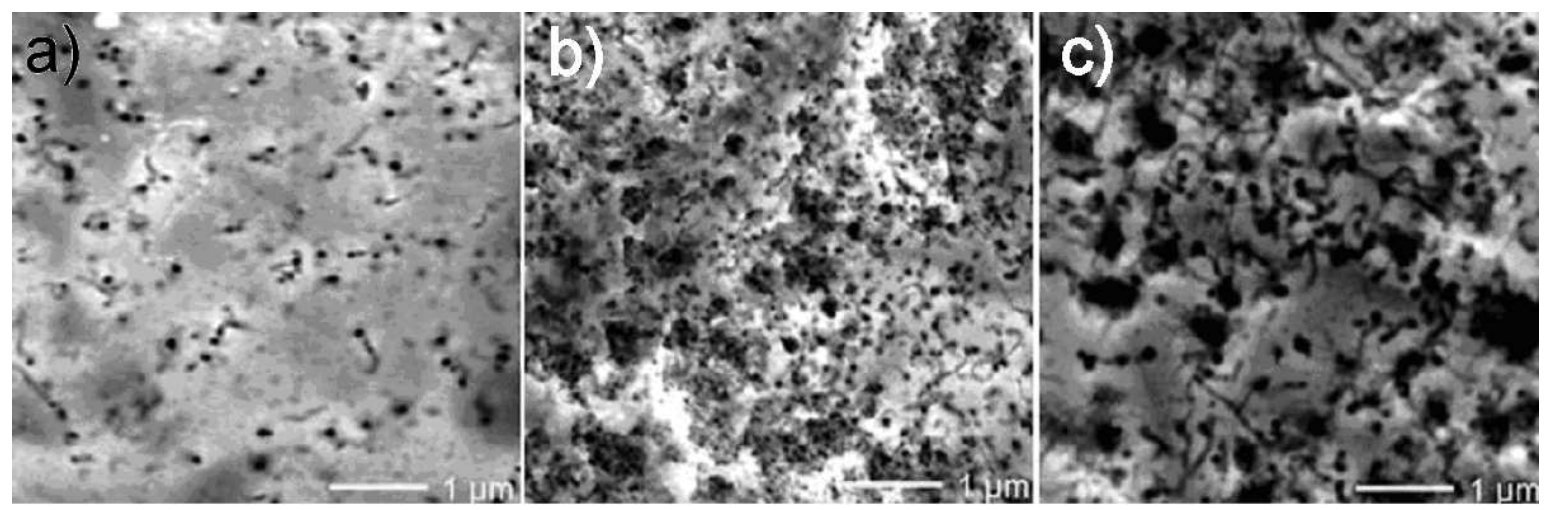

Fig. 3. SEM images of silicon surfaces after MAE during (a) $t=1 \mathrm{~min}$, (b) $t=1.5 \mathrm{~min}$ and (c) $t=3 \mathrm{~min}$. The prolonged etching time induces an increase in both macropore density and macropore diameter.

Table and Fig. 2 illustrate that the metallic fraction of $\mathrm{Pd}$ clusters $F_{\mathrm{Pd}}$ decreases by prolonged immersion time from $F_{\mathrm{Pd}}=71.2 \%$ for $t=1 \mathrm{~min}$ to $F_{\mathrm{Pd}}=61.4 \%$ for $t=3 \mathrm{~min}$. Simultaneously, the $\mathrm{PdO}$ share increases from $F_{\mathrm{PdO}}=28.8 \%$ to $F_{\mathrm{PdO}}=38.6 \%$ for $t=1$ and $t=3 \mathrm{~min}$ respectively. The $\mathrm{Pd} / \mathrm{Si}$ atomic surface ratio obtained from XPS measurements increases from $F_{\mathrm{Pd} / \mathrm{PdO}}=4.8 \times 10^{-3}$ for deposition time $t=1 \mathrm{~min}$ to $F_{\mathrm{Pd} / \mathrm{PdO}}=8.9 \times 10^{-3}$ for $t=3 \mathrm{~min}$. These numbers correspond well to the SEM images in Fig. 1a-c, which present larger particles for the systems with prolonged $\mathrm{Pd}$ deposition time. The increase of the $\mathrm{PdO}$ film coating of the $\mathrm{Pd}$ particle core for longer deposition time is related to both: stronger oxidation in the $\mathrm{PdCl}_{2}: \mathrm{HCl}: \mathrm{H}_{2} \mathrm{O}$ solution and larger $\mathrm{Pd}$ particles for the systems with extended immersion time. Due to the catalytic function of metallic $\mathrm{Pd}$ in porous silicon formation it is important to keep the metallic palladium fraction in Pd clusters as high as possible, which favorites shorter $\mathrm{Pd}$ deposition times. Simultaneously, the $\mathrm{Pd}$ deposition time is a compromise between homogeneous porous silicon formation for high $\mathrm{Pd}$ particle density by longer deposition time and lower $\mathrm{PdCl}_{2}: \mathrm{HCl}: \mathrm{H}_{2} \mathrm{O}$ solution usage for shorter deposition time. In the following experiment all samples receive immersion in the $\mathrm{PdCl}_{2}: \mathrm{HCl}: \mathrm{H}_{2} \mathrm{O}$ solution for $t=1 \mathrm{~min}$.

The catalytic effect of the $\mathrm{Pd}$ cluster enables etching of the mc-Si wafer in an $\mathrm{HF}(40 \%): \mathrm{H}_{2} \mathrm{O}_{2}(30 \%): \mathrm{H}_{2} \mathrm{O}$ solution in a 25:100:20 ratio. Figures $3 \mathrm{a}-\mathrm{c}$ display porous silicon formed by MAE in a $\mathrm{HF}: \mathrm{H}_{2} \mathrm{O}_{2}: \mathrm{H}_{2} \mathrm{O}$ solution for etching times from $t=1 \mathrm{~min}$ to $t=3 \mathrm{~min}$. The prolonged $\mathrm{HF}: \mathrm{H}_{2} \mathrm{O}_{2}: \mathrm{H}_{2} \mathrm{O}$ etching time induces an increase in both macropore density and macropore diameter. 


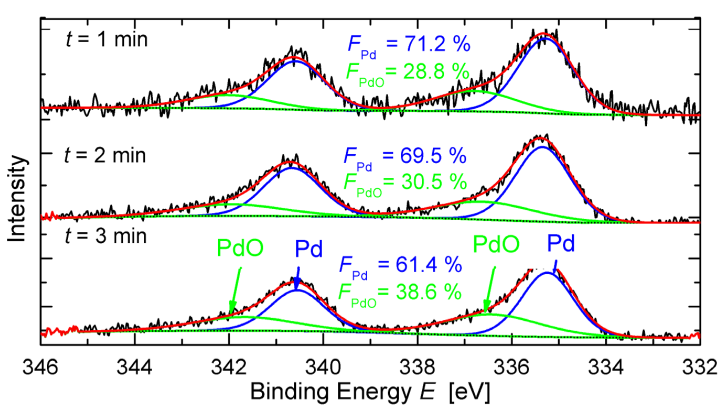

Fig. 2. XPS of $\mathrm{Pd}$ cluster for $\mathrm{PdCl}_{2}: \mathrm{HCl}$ immersion time from $t=1 \mathrm{~min}$ to $t=3 \mathrm{~min}$. With prolonged immersion time the $\mathrm{Pd}$ metal fraction decreases whereas $\mathrm{PdO}$ fraction in $\mathrm{Pd}$ clusters increases.

For detailed porous silicon characterization the setup consisting of a HeCd laser with $\lambda=325 \mathrm{~nm}$, a monochromator (Jobin Yvon HR 460) and CCD camera (Jobin Yvon Symphony BIUV) measures the sample photoluminescence spectra under constant laser fluence.

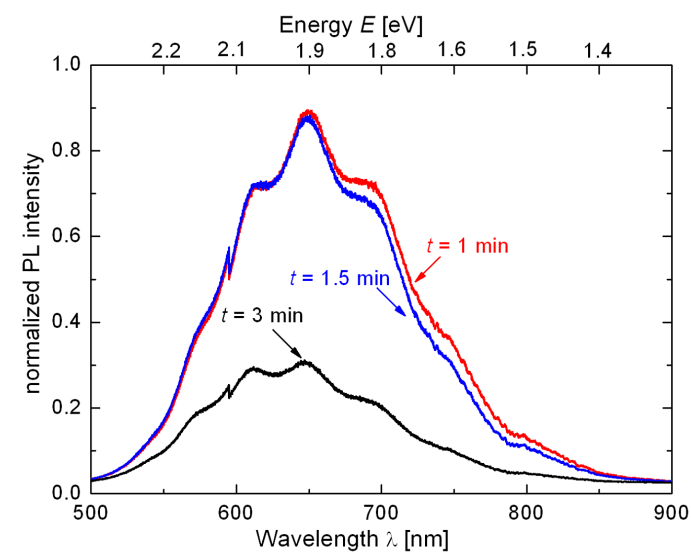

Fig. 4. PL spectra of porous silicon formed on the mc-Si by MAE. The maximum of the PL peak is centered at $\lambda=650 \mathrm{~nm}(E=1.9 \mathrm{eV})$ with a FWHM $=0.3 \mathrm{eV}$ independent of the etching time. The intensity of the PL spectra strongly decreases for extended etching time $(t=3 \mathrm{~min})$ due to increase of layer macroporosity, which reduces amount of the light emitting nanocrystallities.

Figure 4 displays normalized photoluminescence spectra of MAE porous silicon for different etching times. As illustrated, samples show the strong photoluminescence when exposed to ultraviolet light. Independent from the etching time, the maximum of the PL peak is centered in the red part of the spectrum at $\lambda=650 \mathrm{~nm}(E=1.9 \mathrm{eV})$ with a full width at half maximum $\mathrm{FWHM}=0.3 \mathrm{eV}$. These results are well understood on the basis of the quantum-confinement model, where the emission energy

$$
E=E_{0}+\frac{3.73}{d^{1.39}}
$$

is shifted towards blue light with respect to the band gap of bulk silicon $E_{0}=1.17 \mathrm{eV}$ and correlates with the nanocrystallite size $d[8]$. Independently of the etching time the nanocrystals with dimension of $d=3.2 \mathrm{~nm}$ dominate, which is similar to those found for MAE of highly resistive silicon [9]. Simultaneously, the intensity of the PL spectra strongly decreases for extended etching time $t=3 \mathrm{~min}$. This behavior is attributed to the increase of layer macroporosity, which strongly reduces amount of the light emitting nanocrystallites. Figure 3c validates this assumption as it shows a higher macroporosity of the sample and bigger macropore diameter after three minute etching.

\section{Conclusion}

This paper shows that immersion of $\mathrm{Si}$ wafer in $\mathrm{PdCl}_{2}$ solution creates nanometer sized palladium clusters as a catalyst for MAE. It is found that the optimal time of $\mathrm{Pd}$ deposition is one minute. Longer immersion time causes Pd oxidation and increases size distribution of the Pd clusters. Short time of Pd deposition is profitable for industrial application due to lower $\mathrm{PdCl}_{2}$ solution usage and still homogeneous formation of light emitting porous silicon.

The maximum of the PL peak is centered in the red part of the spectrum at $\lambda=650 \mathrm{~nm}(E=1.9 \mathrm{eV})$ and it is independent of $\mathrm{HF}: \mathrm{H}_{2} \mathrm{O}_{2}: \mathrm{H}_{2} \mathrm{O}$ etching time. On the basis of the quantum-confinement model the nanocrystals with dimension on $d=3.2 \mathrm{~nm}$ dominate in porous silicon formed by MAE. Simultaneously, the intensity of the PL spectra strongly decreases for extended etching time $t=3 \mathrm{~min}$. This effect can be explained by lower density of nanopores and higher density of macropores for longer etching times.

\section{Acknowledgments}

This work has been partially supported by the Ministry of Science and Higher Education in the frame of the national network "PV-TECH". The authors would like to thank Jens Kistner from Insitute of Physical Electronics for the photoluminescence measurements and Michael Reuter for a fruitful discussion.

\section{References}

[1] L.T. Canham, Appl. Phys. Lett. 57, 1046 (1990).

[2] X. Li, P.W. Bohn, Appl. Phys. Lett. 77, 2572 (2000).

[3] S. Koynov, M.S. Brandt, M. Stutzmann, Appl. Phys. Lett. 88, 203107 (2006).

[4] T. Hadjersi, N. Gabouze, N. Yamamoto, C. Benazzouz, H. Cheraga, Vacuum 80, 366 (2005).

[5] C. Chartier, S. Bastide, C. Levy-Clement, in: Proc. 22nd Europ. Photovoltaic Solar Energy Conf., Eds. G. Willeke, H. Ossenbrink, P. Helm, (WIP-Renewable Energies, Munich 2007, p. 1231.

[6] K. Tsujino, M. Matsumara, Electrochim. Acta 53, 28 (2007).

[7] NIST X-ray Photoelectron Spectroscopy Database, http://srdata.nist.gov/xps .

[8] C. Delerue, G. Allan, M. Lannoo, Phys. Rev. B 48, 11024 (1993).

[9] T. Hadjersi, N. Gabouze, N. Yamamoto, K. Sakamaki, H. Takai, A. Ababou, E.S. Kooij, Phys. Status Solidi C 2, 3384 (2005). 